\title{
Sins of the Sons of Samuelson: Vision, Pedagogy, and the Zig-Zag Windings of Complex Dynamics David Colander* and Casey Rothschild
}

JEL Classifications: A10, A2, B10

\begin{abstract}
:
The standard economics text is centered on a vision of a naturally self-regulated, dynamically stable system with a unique global attractor. This paper discusses how we got there and how recent developments in the study of dynamical systems allow us to go beyond that. It traces the evolution of the teaching of economics from Alfred Marshall, who built his supply-and-demand framework within a complexity vision of the economy. It suggests that that complexity vision was lost as economists formalized the supplydemand framework and extended it to the entire economy. This paper argues that the current textbook presentation of economics should not and cannot serve as the only intellectual frame we provide to our students.
\end{abstract}

Key words: vision, complex dynamics, stability, economic pedagogy

* Corresponding Author. Both at Middlebury College, Department of Economics, Middlebury, VT 05753 


\title{
Sins of the Sons of Samuelson: Vision, Pedagogy, and the Zig-Zag Windings of Complex Dynamics David Colander* and Casey Rothschild
}

\begin{abstract}
When the force of the impact is spent, he comes to rest, a selfcontained globule of desire as before. - Thorstein Veblen
\end{abstract}

In 1967, Paul Samuelson wrote that the ambiguities in Marshall's work had "paralyzed the best brains in the Anglo-Saxon branch of the profession for three decades." (Samuelson, 1967, 109) His point was that many of the ideas in Marshall's Principles (1890) could be much more easily expressed in mathematics than, in Edgeworth's words, the "zigzag windings of the flowery path of literature."1 (Edgeworth 1925, 288) This zigzag description fits Marshall's approach, as one can see when reading Principles. Formal models are put in appendices, and the discussion uses literary flourishes that modify most strong conclusions. This style reflects Marshall's broader methodological approach which eschewed too heavy reliance on mathematics. See, for instance, his well-known diatribe against the use of "mathematical-economics" in which he stated that "a good mathematical theorem dealing with economic hypotheses was very unlikely to be good economics" and that economists should burn the mathematics. (Pigou, Memorials, p. 427.)

Marshall made his sharp comments against the use of mathematics in economics because he maintained a more Classical methodological position which saw models as providing at best what J. S. Mill (1838) called half truths, which had to be combined with common sense and metis (knowledge of the system gained from being part of the system) to arrive at any policy conclusion. ${ }^{2}$ For Mill and Marshall economic policy was an art, not a science, and in their presentations of economics to students the art comes through. Marshall's partial equilibrium approach saw economic theory as an "engine of discovery," not a set of theories to be followed. ${ }^{3}$

In the early and mid-1900s that Classical methodological approach was being replaced by a more distinctly mathematical method, as mathematically oriented economists showed fallacies in general arguments held by previous economists and cleared up confusions. Economists such as Irving Fisher, John Hicks, Abba Lerner, and Paul Samuelson all made important contributions to theory. As the power of mathematics became clear, the Classical method, which Marshall had maintained, lost adherents, and a new methodology replaced it in the science of economics. More and more economists came to

\footnotetext{
${ }^{1}$ Edgeworth claimed that this particular quotation was not meant as a direct attack on Marshall. In the preface to a reprinting of his paper (Edgeworth, 1925) he points out that he had written it before the publication of Marshall's Principles. But it was interpreted as an attack, which is why Edgeworth felt the need to claim that it was not. Actually, since Marshall's Principles had been in development for twenty years before it was published, and since Marshall's views and approach were well known, the fact that Edgeworth wrote this before the publication of Marshall's Principles does not necessarily mean that it was not a veiled reference to Marshall, and to the Classical tradition that Marshall followed.

${ }^{2}$ For a nice description of this Classical approach, see Richard Bonk (2009).

${ }^{3}$ For a discussion of the Marshallian method see Landreth and Colander (2002).
} 
believe that if an idea couldn't be reduced to a mathematical model, it was unclear what that idea was, and that it probably wasn’t worth knowing.

Textbooks lagged cutting-edge economics and were slower to change. Maffeo Pantaleoni (1889, translated into English 1898) made an early attempt to change the nature of economic pedagogy, but through the late 1940s most textbooks still followed the Marshallian methodological approach. ${ }^{4}$ It was only when Samuelson wrote his classic textbook that economic pedagogy changed, and Samuelson's Principles (1948) has served as the template for textbooks ever since. Because of the enormous influence of his principles text, Paul Samuelson played an even more influential role in economics than is captured by his many seminal publications in theory. He changed economic pedagogymoving it away from the zig-zag windings of verbal discussion, which highlight the complexity of the economy and downplay economists' analytic models - to a pedagogy that had at its core a constrained optimization framework embodied in a unique equilibrium general equilibrium model of the economy. While beginning students could not be presented with much of the underlying mathematics, they could be taught simplified models and given a sense of the broader mathematical foundations of those models.

Accomplishing this was his intent, and on the title page of Foundations of Economic Analysis (Samuelson 1947), in which he codified large portions of the then-existing formal theory of economists, he quoted J. Willard Gibbs's famous line, "Mathematics is a language." So on both the theoretical front and the pedagogical front, Samuelson was an important player in the movement that led to a fundamental shift in approach of the pedagogy of economics - away from the Classical/Marshallian emphasis that "models provide at best half truths and need to be supplemented by verbal discussions" approach, to an "it's best to concentrate on the highly simplified formal model” approach. Both approaches have problems; the first captures the forest, but blurs the trees; the second captures the trees but blurs the forest. The pedagogy of economics has difficulty finding the appropriate balance between the two.

There is legitimate debate about what Marshall's and Samuelson's true visions of the economy were, but it seems clear that in terms of pedagogy, they chose different paths. Marshall chose to provide as a background vision for students an amorphous model with an ambiguous core, whereas Samuelson chose to provide students with a vision of economics that was best conceptualized within an already tractable mathematical frame-the Walrasian general equilibrium model. ${ }^{5}$

Samuelson's Foundations (1947) provided economic researchers with such a vision, and his Principles (1948) translated it down to students. Through these two books, he helped structure economists' vision of the economy as a naturally self-regulated dynamically stable system with a unique global attractor. ${ }^{6}$ That vision remains pervasive in economic

\footnotetext{
${ }^{4}$ See Colander, (2006a) for a discussion of the nature and evolution of textbooks during this time period.

${ }^{5}$ For a further discussion of these issues see Colander (1995a, 1996).

${ }^{6}$ We are not claiming that Samuelson had difficulty finding a balance between the "half-truths" and

“concentrate on simplification” approaches. Having been trained in the Marshallian vision, he nicely
} 
research and economic pedagogy. It is what students are taught, and what many economists have in the back of their mind when they extend their theoretical work to policy.

\section{IS IT TIME TO TURN SAMUELSON'S CRITIQUE OF MARSHALL ON ITS HEAD?}

In reflecting on the state of economic pedagogy and policy discussions today, a strong argument can be made that Samuelson's critique of Marshall deserves to be turned on Samuelson himself, and that the vision he presented in his text (which has been copied by almost all other texts) has paralyzed the best brains in the Anglo-Saxon branch of the profession for the last three decades. It has hurt economists in both theory and applied policy. It has hurt in theory because it has discouraged them from exploring non-linear dynamic models with multiple basins of attractions and complex dynamics; instead it has led them to emphasize more dotting i's and crossing t's within the Walrasian model. It has hurt applied policy because it prevented economists from exploring a much wider range of policy issues than are captured by constrained maximization models with “appropriate” convexity assumptions.

Within textbook economics, the Walrasian vision still reigns, but theorists have long known the limitations of that vision, and cutting-edge work is now exploring systems with complex dynamics, with work in evolutionary game theory, complex and chaotic systems, systems with multiple equilibria or with temporary but fleeting stability. (See for example, Rosser 1991.) But our undergraduate texts and much of the standard policy discussion, particularly before the 2008 financial crisis, have been almost devoid of any sense that a vision of global stability with a unique attractor would be the strong exception, not the rule, in the mathematics describing any complex system such as the economy.

There are, of course, advantages to studying the behavior of naturally self-regulated, dynamically stable systems with unique global attractors. As a guide to some issues, there is much to be said for such studies; both the conceptualization and the mathematical formalization of such systems are aesthetically unparalleled achievements. But, as recent events in the financial sector have shown, using such studies as the sole guiding vision in economic pedagogy leaves students at a loss to understand many real-world events. That the study of dynamically stable systems with unique global attractors survives today as a universal guiding principle — the only intellectual frame we provide to our studentsborders on professional mendacity.

blended the two. Throughout his writing he showed strong recognition that the economy was more complex than captured by stable models. Similarly, Marshall, having been formally trained in mathematics, recognized that mathematics existed that could have shed light on the issues that he chose to describe verbally. Our focus in this paper is on their pedagogy decisions-how they chose to simplify the enormous complexity of the economy into something that could be taught to undergraduates - and the influence those decisions had on future economists. 
In theoretical economics, the correction of this failing is underway; it involves the use of more sophisticated mathematics, and the use of game theory as the underlying foundation for economics and all social systems. The correction is much slower in pedagogy. Ironically, remediating the pedagogical shortcomings of Samuelson's frame may best be accomplished by a partial return to Marshallian “zigzag windings.” Indeed, Marshall avoided these shortcomings in his Principles (1890) with his flowery language describing potential dynamical problems. He used those verbal descriptions to remind the reader that the supply-and-demand framework was only a partial equilibrium framework relevant for small issues, to be used as an "engine of analysis" when appropriate, and that it should not be applied beyond its limited frame.

Samuelson's pedagogical simplification downplayed these complicating issues and replaced them with an emphasis on supply-and-demand's usefulness, suggesting that its usefulness goes far beyond looking at little markets in isolation, and that supply-anddemand can be used as a general vision of the economy. We will dub this the "Sons of Samuelson" vision - by which we mean it is the vision that students of Samuelson were led to. We don't call it a Samuelson vision because he was trained in a Classical/Marshallian vision, and, in his technical writings, he recognized that the issues were much more complicated than captured in the pedagogical models of the textbooks, and was open to alternative approaches. His knowledge of earlier writings within economics was legendary within the history of thought profession, and his work on the multiplier-accelerator model, which he emphasized in his Nobel Lecture (Samuelson, 1972) demonstrated his recognition that the issues were much more complicated than those captured in the textbook model. ${ }^{7}$ But in the words of Samuelson (describing Ragnar Frisch's work) "a great man's work can, in its impact on lesser men, have bad as well as good effects.” (Samuelson 1974.)

To see the difference in the vision of the economy students are presented with in Marshall, and in the modern textbooks, consider Marshall's verbal description of the stability of a supply-demand equilibrium. Marshall writes:

When demand and supply are in stable equilibrium, if any accident should move the scale of production from its equilibrium position, there will be instantly brought into play forces tending to push it back to that position; just as, if a stone hanging by a string is displaced from its equilibrium position, the force of gravity will at once tend to bring it back to its equilibrium position....

But in real life such oscillations are seldom as rhythmical as those of a stone hanging freely from a string. The comparison would be more exact if the string were supposed to hang in the troubled waters of a millrace, whose stream was at one time allowed to flow freely, and at another partially cut off. Nor are these complexities sufficient to illustrate all the disturbances with which the economists and the merchants alike are forced to concern themselves. If the person

\footnotetext{
${ }^{7}$ We are thankful to an anonymous referee for directing us to this work.
} 
holding the string swings his hand with movements partly rhythmical and partly arbitrary, the illustration will not outrun the difficulties of some very real and practical problems of value. For indeed the demand and supply schedules do not in practice remain unchanged for a long time together, but are constantly being changed; and every change in them alters the equilibrium amount and the equilibrium price, and thus gives new positions to the centres about which the amount and the price tend to oscillate. (Marshall, 1920, 346-347.)

As Rosser (1991) points out, the metaphor in this passage is a system that exhibits chaotic, or at least partially chaotic, dynamics. Recognition of that fact would require economists to analyze such a system meaningfully and require an interdependent system of equations involving, at a minimum, complex higher-order differential equations and potentially non-computable solutions. The solutions to such systems can be far from simple; they may exhibit path dependency and sensitive dependence on initial conditions, and the many other elements that non-linear mathematicians have highlighted in their analyses of complex systems.

That is not the vision presented in the modern texts. The vision that modern economics textbooks construct starts with - and in most cases ends with — is a stable partial equilibrium Marshallian supply and demand vision. In it markets are buffeted away from the unique "natural state" at the intersection of supply-and-demand. "Market forces" push us back, like gravity and friction bringing a ball to rest at the bottom of a bowl. This is a useful metaphor, but it is tendentious to apply it too broadly, since the norm (if such a thing can be said to exist) for complex dynamical systems is constant motion with multiple attractors. Hart and Mas-Colell's (2003 p. 1830) assertion that "it is notoriously difficult to formulate sensible adaptive dynamics that guarantee convergence to Nash equilibrium" reflects the peculiar vision cultivated within the profession: a non-economist student of dynamical systems would naturally tend to visualize dynamic systems as nonconvergent. She would be surprised not by the difficulty of finding such dynamics, but, on the contrary, if it turned out to be easy to generate such stability.

Economists might reasonably hope that stability is more common in economic systems, where it can be saved by imputing "theorizing and foresight to the players" (Sargent 2008, 27). It is not, however, at all clear to us that we should expect purposeful forwardlooking agents to provide a stabilizing force (other than the hope that they may be able to put the system together when it collapses), except possibly in the case that all agents are "infinitesimally small" and thus have no market power. Computationally meaningful "top down" analysis of models with multiple forward-looking, strategically linked agents is simply not tractable with current analytical techniques - and it may never be. But even if theorizing and foresight can stabilize such a model, the presence of non-infinitesimal agents (with market power) still undermines the Sons-of-Samuelsonian vision of a unique global attractor. Sargent (2008), for example, discusses how learning within models with a single non-infinitesimal agent (the government) can only ensure convergence to a stable self-confirming equilibrium. Since there may be self-confirming equilibria, convergence to the most preferred equilibrium is not guaranteed. 
The current dynamic stochastic general equilibrium (DSGE) consensus ${ }^{8}$ approach to modeling macroeconomic systems effectively ignores the dynamic foundations of equilibrium. Modern macro researchers employing DSGE models simply define equilibrium for the setting they consider, and then calculate (or approximate) it and describe its properties. Presumably, the utility of such models is predicated on the hope that equilibrium is a useful approximation to reality; but there is typically no introspection about whether achieving equilibrium in their setting is compelling, or whether the abstractions they make to achieve tractability-e.g., assuming a representative agent - tip the scales towards making the implicit equilibration dynamics more stable. Saari and Simon's (1978) results on the implausibly strong informational requirements necessary to justify dynamic stability of equilibrium in multi-agent settings suggest that such introspection might substantially undermine faith that equilibrium is as useful an approximation to reality as the DSGE consensus approach seems to assume. But our argument is not about whether such introspection would (or should) undermine the DSGE consensus. Our argument is about pedagogy. We accept, for example, that top theorists appreciate the poor dynamic foundations for assuming equilibrium and use the model with the appropriate qualifications and nuance. That's what makes them top theorists. Our argument is that for students, and for the vast majority of practical research using the DSGE framework, the question of how (or how quickly, or even whether) equilibrium is likely to be achieved is completely ignored. We view this as prima facie evidence that the Sons of Samuelson's Walrasian vision has paralyzed the minds of economists.

We want to emphasize that we do not attribute any narrow vision or paralysis-of-mind to Samuelson, nor to his close colleague Robert Solow. They maintained a far more eclectic, might we say Marshallian, or at least Keynesian, vision of aggregate economy. It is the students who studied Samuelson's and Solow's work without the benefit of having studied and absorbed the broader Classical/Marshallian vision who were susceptible to what McCloskey (1996) calls the Samuelsonian vice. (We believe that it is better called the "Sons of Samuelson" vice. Samuelson was much more careful than his students, and his students' students, in pointing out that the limitations of the models must be used with care. $)^{9}$ Samuelson and other early macro economists treated their macro models much more loosely, which made them worry less about the underlying connection of the models with microeconomics. They saw equilibrium models as tools to use to shed light on problems, not as the actual descriptions of the state of the economy. For example, Samuelson $(1996,163)$ tells the story about the description his teacher, Edward Bidwell Wilson, gave of equilibrium in relation to an automobile tire: since air is continuously

\footnotetext{
${ }^{8}$ For a discussion of the consensus, see, for example, Blanchard (2008a).

${ }^{9}$ As we alluded to above, a small number of the most innovative of macro researchers (e.g., Sargent 2008) recognize and have begun to struggle with the importance of "microfounding" stability, typically via evolutionary learning metaphors, combined with assumptions of rationality. One needs two implicit assumptions for this approach to work: first, that individuals learn quickly about the information in the system so that we can treat them "as if" they have that information, and, second, that they have explored the topography of the entire space, not just explored locally. Neither of those assumptions seems reasonable to us, yet they are central to deciding whether to accept the DSGE vision. The actual learning dynamics that are central to such a judgment are currently beyond the modeling capabilities of macro economists.
} 
escaping, the unique true equilibrium of the tire is when the tire is flat. But in a realworld frame, we can operate as if the equilibrium of the tire involves the air pressure staying constant in the tire. Samuelson's point in telling this story was that intuition, and sensibility about the relevance of assumptions to models, has to guide the choice of what equilibrium concept to use in modeling. When they do not, models paralyze the mind rather than clarify understanding.

In his Principles, Marshall carefully avoided emphasizing models that might lead students to a unique stable equilibrium framework. In it there are few supply-and-demand diagrams, and his verbal discussions of supply-and-demand are laced with addenda and qualifications. In modern texts that has changed. Today, there are many more supply-anddemand diagrams, much more emphasis on the technical manipulation of supply-anddemand in the graphs; and far fewer addenda and qualifications to the models. Indeed, the only significant addendum offered in modern texts is the case of externalities. Students learn that the presence of externalities undermines the assumption that equilibrium is normatively appealing, but the very externality framework maintains, part-and-parcel, the unique-and-globally-stable-attractor "frame" of the Marshallian supply-and-demand model, and further cements it into students' minds.

Whether or not this frame is in fact a good approximation, or at least a fruitful unifying vision for economic research (and, in case you did not guess from what we have written, we certainly have our opinions on the subject), there is no question that its stranglehold on economic pedagogy needs to be broken. Foley (2009) argues that cultivating the alternative complexity frame would help to make economics more "fertile and interesting.” We wholeheartedly agree, and have argued elsewhere that the complexity frame is useful for unifying current undergraduate and graduate macroeconomics pedagogy. (Colander and Rothschild 2009). ${ }^{10}$

Ultimately, we suspect that the change will likely take place as game theory becomes the core of the textbooks, just as it already has become the core of theoretical analysis of microeconomics. Bowles’ Microeconomics (2006) provides an initial attempt at making the change. But the movement to a game theory foundation requires an enormous jump that most introductory professors would be unwilling to make. The path to a full complexity frame based upon game theoretic foundations will be long and hard. Thus, we argue here not for a part-and-parcel replacement of frames, but for the more modest goal of a short-term "patch": we argue for introducing and demonstrating alternative complex system visions within the supply-and-demand paradigm, so that vision of the universality of stability has less chance to become deeply ingrained in students.

The intuition behind our suggested patch is straightforward. The current, Samuelsonian, approach first presents the simple supply-demand model, and argues plausibly that it has

\footnotetext{
${ }^{10}$ There are a variety of dimensions of complexity and what is meant by complexity, and the complexity frame or vision, is subject to significant debate. See, for example, Rosser,1999, and Colander, 2000. We take no specific stand on these debates, and what we mean by complexity is that the various dimensions of modeling problems that complexity raises are taken seriously—-that is, introduced to students, within economic pedagogy.
} 
stable dynamics that lead inexorably to a normatively appealing equilibrium. It then "bootstraps" this vision to more complex systems - where, we are arguing, it is inappropriate and misleading. Short of a complete change of frame, there are at least two natural approaches for fixing this: one is to teach that the simple supply-demand intuition does not generalize. Another is to show that dynamics can, in fact, be incredibly complex even within the superficially simple supply-demand framework. From a theoretical perspective, the former approach is more appealing: the supply-demand vision is inappropriate precisely because the intuition underlying it doesn't generalize to more complex systems. ${ }^{11}$ However, since we believe that, once inculcated, it is difficult to "unlearn” a stability vision we argue that on practical grounds the latter approach serves as a more useful patch.

The typical student learns when studying stability in the supply-demand model that deviations from the equilibrium price are naturally "self-correcting:" prices that are too high lead to surpluses, which tend to make prices fall, while prices that are too low lead to shortages and, consequently, price increases. This reasoning is too facile for multiagent systems with imperfect information. For example, with appropriate assumptions simple predator-prey models exhibit natural feedback: having too many predators is "naturally" self-correcting, as is having too few. But this does not ensure a harmonious mix. Instead, large numbers of predators set the stage for their own collapse and the subsequent rise of prey populations, which in turn sets the stage for a boom in predators. Ostensibly self-correcting forces lead not to equilibrium but to a perpetual "boom-bust" cycle.

This “destabilizing”_ or at least, "cyclical”_feedback metaphor is intuitively plausible-hence teachable-in economic systems as well. For example, low global oil prices can lead to overinvestment in oil-heavy vehicle, housing, and industrial stocks, which sets the stage for a period of high oil prices, which in turn leads to investment in oil-lean technologies, which in turn drives oil prices down. Early economists recognized this and the multiplier accelerator model was a fixture in early macro texts, but it has since disappeared.

In the remainder of this paper we expand upon these ideas. First, we provide several examples, drawn largely from the popular press, about how supply-and-demand reasoning and its broader vision is misapplied. We emphasize how this is due to a lack of competing, alternative visions. In the second section, we discuss specifically how contemporary pedagogy inculcates a narrow vision. Then we offer an example of how this lack of alternative visions can lead economists to go very wrong in their policy advice. Finally, we briefly outline our view of how to begin to cultivate alternative visions. We argue that a thoughtful discussion of disequilibrium dynamics within the

\footnotetext{
${ }^{11}$ An additional advantage of this approach would be that it would facilitate an emphasis on the sadlyneglected "fallacy of composition" that, in our view, should be underpinning a curricular (and appliedresearch) distinction between macro and micro economics. Good theorists clearly appreciate the Sonnenschein (1972)-Mantel (1974)-Debreu (1974) results that micro-intuitions may not apply to macrobehavior, but pedagogy (and much of the "on the ground" research) still centers on models where the macro-behavior is just a reflection of the explicitly constructed micro-intuitions.
} 
basic supply and demand framework can be used to illustrate a wide variety of different patterns of behavior, with the hope that illustrating the incredible richness of dynamics that can emerge in simple settings is a helpful first step in cultivating distinct global visions and preventing what Duncan Foley has called an “'autistic' fixation with equilibrium analysis.”

\section{MISAPPLICATIONS OF THE SUPPLY-AND-DEMAND VISION}

In modern textbooks, equilibrium supply-and-demand (S-D) reasoning is universal, but the sensibility to know when it can be usefully applied seems to be almost universally lacking. This lack of sensibility-training is reflected throughout the media. Following the business press and economic forecasters in their discussion of the oil price gyrations in 2008 perfectly illustrates the absurdity of the S-D “vision,” applied uncritically.

On July 7, 2008, with oil prices nearing \$150 a barrel, the Wall Street Journal ran an article headed “Oil’s rapid rise stirs talk of \$200 a barrel this year,” (King 2008) and helpfully followed by noting: "Long list of factors keeping prices high.” Two months later, on September 11, with oil prices nearing \$100 a barrel, it thoughtfully noted: "The oil market dropped in spite of the Organization of Petroleum Exporting Countries' move to cut back oil output, reflecting distrust of the cartel's ability to enforce quotas and fears that world consumption growth will sputter further.” (Meyer 2008.)

When a model fails to predict major movements in advance, and can explain anything expost, it is simply not a useful model. Even more problematic, in our view, is the vision of a natural self-correcting mechanism leading the market back to some "right" price inspired by thinking exclusively within the S-D paradigm. This leads analysts who recognize that S-D may not be predictively helpful in explaining short run fluctuations to retain an implicit faith in the market to return to the "right" price in the long run.

“The run-up to $\$ 147$ was clearly overdone, but I think selling down past \$120 or \$100 was overdone, as well,” said Michael Fitzpatrick, vice president for energy risk management at MF Global Ltd. In New York. “There's a general acknowledgement of fundamental valuation aside from all this financial-market hubbub.” (Johnson 2008, November 18.)

Trying to shoehorn an unpredictable world into a vision with a unique, stable, globally attracting fixed point is precisely what leads to the absurdities that characterize the discussion of oil prices, and the pervasive and vapid discussions of preceding days' stock and commodity price movements.

Following discussions of oil prices in the press, or listening to economists' comments on TV or radio, one quickly sees the trivial sense in which price is determined by supply and demand: if price goes up, it is "always" because supply decreased or demand increased or some combination of the two. Sometimes this is useful and constructive. In the late 1990s, for example, prices of Atlantic bluefin tuna plunged. The Boston Business Journal (Holland 1998) attributed this to "the depressed economy in Japan," among other things. 
Thereafter, the price rose dramatically. The Washington Post (Harden 2007, November $11,2007)$ attributed this to the contraction in supply resulting from smaller fishing quotas in Japan (which were in turn a response to depleted stocks). Insofar as these events were sufficiently strong empirically, these were predictable movements in price, and the ex post explanations are plausible and instructive.

More generally, however, the reality is richer and more complicated than simple supply and demand would suggest. Consider the market for chocolate: from 2006 to 2008 the price of a ton rose from $\$ 1500$ to $\$ 2600$. Unlike in the bluefin tuna case, the data do not reveal any apparent shifts in either supply or demand. Delving deeper, it appears that the proximate cause of the rise in prices was hedge funds moving their investments out of real estate and into commodity futures. (Oil and grains also experienced sudden large increases in price during this same time period, for example.) Hedge funds increased their demand for chocolate futures from 260,000 tons to 706,000 tons, or $20 \%$ of the market.

One can certainly shoehorn this story into the supply-and demand-framework, simply by asserting that there was an increase in demand resulting (indirectly) from hedge funds and speculators. The problem with doing so is that once we have a model with speculators and forward-looking decisions, we cease to be in a setting where partial equilibrium reasoning applies. We are no longer justified in invoking notions of dynamic stability and unique globally attracting "natural" prices. We can still talk in terms of "supply-and-demand," but we can no longer cavalierly invoke its vision. Speculation can be a stabilizing force, but there is no guarantee that it will be, and blithe assertions that it must be are precisely what we are criticizing here: we need to avoid the "autistic" fixation on the supply-and-demand equilibrium vision and to be aware that completely different dynamic structures may apply. ${ }^{12}$

Inspired by his mother's complaints about gas price increases in response to Hurricane Ike, Alex Tabarrok (September 14, 2008) writes:

Price is never, ever, determined by historical cost. Price is determined by supply and demand. If supply or demand change then the price changes regardless of historical cost... In the present situation the supply of gas has been reduced and the price has gone up.... Is the high price due to supplier gouging? Not at all. It's buyers who push up prices in a competitive market and it's suppliers who push prices down! ... as the situation stabilizes suppliers increase the quantity supplied until price is pushed down towards long-run costs (which are also historical costs).

We are inclined to agree with most of Tabarrok's conclusions. Our objection is to the implicit vision of an automatically self-stabilizing system he invokes to reach it. The vision precludes the very possibility of supplier gouging, while common sense tells us

\footnotetext{
${ }^{12}$ In fact, one might expect hedge funds to be trying to be locally unstabilizing to create an environment in which they can profit from the disequilibrium adjustment path. We say this because hedge funds employ highly sophisticated mathematical economists and the study of complex dynamics and behavioral economics has progressed to the point where it should be possible to take advantage of people's predictable irrationality in disequilibrium adjustment processes.
} 
that these sorts of situations are precisely the ones where suppliers may well be successful in pursuing price-gouging policies. There is certainly no strong theoretical justification for the assumption that prices will immediately adjust to the intersection of supply and demand curves at every instant. And, when supply and demand are determined in large part from unstable expectations, we cease to be in a setting where the Mashallian vision necessarily applies, and it is not clear that anything ever ensures a rapid convergence to back to the intersection of supply and demand.

Clearly, to employ the S-D frame properly, one needs a certain sensibility about when it is and is not useful. (We are inclined, on the basis of our sensibilities, to think that Tabarrok's analysis is reasonable, while much of the analysis of oil price fluctuations is not. In both cases, though, it is crucial to keep in mind that the S-D vision may not be applicable.)

Someone coming out trained in Marshallian/Classical vision would have just such a sensibility, and would be someone with a natural affinity for the complexity frame. She would likely be someone who, in Nobel Laureate Robert Solow's (2008, 246) words, would have a "general preference... for small, transparent, tailored models, often partial equilibrium usually aimed at understanding some little piece of the (macro-) economic mechanism." ${ }^{13}$ So there is a certain irony to the role played by the Marshallian S-D vision of the world created by the profession's integration of the Marshallian S-D model into a Walrasian framework in the modern textbook. Not only are students denied training in correctly applying the S-D model, but they are effectively prevented from visualizing systems that are anything other than naturally and globally stable. As Solow's statement and Marshall's vision suggest, partial equilibrium modeling is actually useful precisely because it is a tool for looking at pockets of local order in a system too complex to analyze globally. These pockets of order are not pieces of a globally stable system, and, indeed, may only be stable because they are supported by self-organizing or governmentimposed institutions.

Instead of visualizing the economy within a complexity vision, wherein we hope to gain traction on small islands of order, we find ourselves visualizing the economy as a "giant" supply and demand model, where stability is globally enforced by the "magic of the market." These stories take many forms, but they all attribute some almost mystical property to the ability of the "market" to coordinate economic activity without a central controller. Hazlitt (1948) provides a beautiful illustration of this vision:

The private enterprise system, then, might be compared to thousands of machines, each regulated by its own quasi-automatic governor, yet with these machines and their governors all interconnected and influencing each other, so that they act in effect like one great machine... Thus every departure from the desired speed itself sets in motion the forces that tend to correct that departure... It is precisely in this way that the relative

\footnotetext{
${ }^{13}$ Colander (2007) argues that Solow’s "piecemeal” approach to teaching his students was lacking a motivating complexity vision.
} 
supply of thousands of different commodities is regulated under the system of competitive private enterprise (96-97).

Hazlitt's “one lesson” follows directly from this vision of global self-regulation-indeed, the book is among the best articulations of that vision ever constructed. But the book was written in response to the growing popularity of Keynesianism, and, as a critique of Keynes, it can only be viewed as a failure: Keynes' entire argument was founded on the inappropriateness of the underlying "self-regulating" vision. A re-articulation, however eloquent, of that vision does not constitute a response.

Nevertheless, Hazlitt's vision-not Keynes'—is the one that dominates today. Sixty years later, the same basic yarn is spun by Harford (2005) in The Undercover Economist:

Every product would be linked to every other product through an ultra complex network of prices, so when something changes somewhere in the economy...everything else would change-maybe imperceptibly, maybe a lot— to adjust. (71)

Sure, there are caveats in modern treatments: market efficiency relies on perfect information, no externalities, and so forth. And, to be fair, Harford is quite careful in describing this scenario as "fanciful" rather than a realistic description of the world. But the underlying vision of a self-regulating system remains.

We now turn to a specific discussion of how the current pedagogical approach inculcates and then reinforces this misguided vision.

\section{THE PEDAGOGICAL INCUBATION OF THE STABILITY VISION}

The current pedagogical approach in economics can be summarized as follows: First, unify all of economics with the notion of equilibrium. Second, justify and illustrate equilibrium by focusing exclusively on the S-D model, where equilibrium is plausibly dynamically and globally stable. Third, illustrate future examples of equilibrium by an explicit appeal to dynamic stability whenever the examples can plausibly be plausibly be argued to be dynamically stable, and suppress any discussion of dynamics when the dynamics would not obviously be stabilizing. Viewed from a distance, it is almost as if we actively want to indoctrinate our students to believe in the magic of the market.

It is worth being specific about situations in which equilibrium is explicitly discussed in undergraduate (and to a lesser extent, graduate) curricula. We first discuss cases where equilibrium is plausibly stable, and in which dynamic stability is typically discussed explicitly (if uncritically). We then turn to situations where equilibrium continues to be discussed, but in which dynamic stability is less plausible and dynamics are typically ignored.

\subsection{Examples where Stability Is Discussed}


Students are introduced to the notion of equilibrium via the Marshallian partial equilibrium supply-and-demand (S-D) framework. They are taught that supply and demand are, respectively upward and downward sloping functions of price. The equilibrium price is defined as the unique intersection of these two lines- the unique price for which the "market clears." At higher prices, supply exceeds demand, leading to a surplus, which puts downward pressure on prices, pushing us back towards equilibrium. Symmetrically, prices that are too low cause shortages, which naturally pushes prices back toward equilibrium again. This is students' first conception of equilibrium: it is unique, and it is a globally stable attractor. In the model, out-of-equilibrium prices are conceivable, but they are naturally self-correcting, so they are quickly dismissed and the "dynamics" pursued thenceforth amount to the comparative static comparisons of equilibria.

The S-D framework also teaches students that equilibrium is normatively appealing (it maximizes total surplus). This conception is later reinforced when the idea of the "long run" is introduced for perfectly competitive markets: if the short-run equilibrium price is higher than the minimum of the long-run average total cost curve, firms enter the market, driving prices down. Symmetrically, low prices lead firms to exit the market, which eventually will drive prices back up. Thus, "in the long run” prices are naturally driven to a unique global attracting state: the normatively appealing minimum of the average total cost curve. What that misses is the fact that if a market is in constant flux and has multiple equilibria, there is no well-defined market price to serve as signal.

The "aggregate supply" and "aggregate demand" models used in introductory macroeconomics courses more or less reason by (false) analogy to simple supply-anddemand. A serious discussion of equilibration dynamics is postponed until intermediate macroeconomics (where it is at best only superficially dealt with), a course that typically only students majoring in economics take.

Those who do go on to major in economics are typically introduced to the Keynesian Cross model, a centerpiece of many intermediate macroeconomics courses (Blanchard 2008b), and a second example of a pedagogical tool in which "stabilizing” equilibrium dynamics are explicitly discussed. In this model, aggregate planned expenditure is an upward sloping function of income (output). "Equilibrium” occurs when income is equal to planned expenditures. This equilibrium is justified by a heuristic dynamic story completely analogous to the basic S-D dynamic reasoning, but with only quantity adjustments: When output (income) exceeds aggregate expenditures, more is produced than is desired. This leads to unintended inventory accumulation, which in turn leads firms to cut back on production, decreasing output. The economy "naturally" adjusts back to the unique intersection of two curves again.

That the Keynesian Cross model is the primary theory associated with Keynes in the undergraduate curriculum is more than a little ironic. Our interpretation of Keynes' General Theory is that it was an attempt to articulate how a complex system like the macro economy can exhibit multiple equilibria and may not exhibit the globally stable 
and self-correcting nature suggested by Marshallian supply and demand analysis. ${ }^{14}$ It was an extension of the Marshallian biological complexity vision of the aggregate economy, one designed to supplement the Marshallian supply-and-demand vision of small markets within the economy. As is clear from the history of Keynesian economics, it was not a successful attempt. Keynes' glimpse of a complexity vision was quickly lost as his ideas were translated into a Walrasian multi-market equilibrium framework, and the Keynesian Cross shell of his vision is now simply another example of a S-D-like global stability.

The policy implications derived from the Keynesian Cross model are similarly "nonKeynesian" and, indeed, reflect a vision far closer to the self-correcting vision of Marshallian supply-and-demand than Keynes' complexity vision. The model purports to illustrate how the economy can be "stuck in a rut" by illustrating how changes in sentiments can lead to equilibria with output below full employment. In Keynes' vision, these pathologies arise because the economy is a complex dynamic system without a unique and globally attracting fixed point. The periods of relative stability between crises are supported by a whole host of government and self-organizing institutions. These institutions may impose rigidities that superficially create unemployment, but they are integral in helping to create "pockets of order" so that the economy can successfully coordinate in an intrinsically unstable dynamic environment. The key to macro policy is helping to get the institutions right. That, in our view, was the essence of the Keynesian vision. The Keynesian Cross model (and the entire neoKeynesian-neoclassical synthesis) gives precisely the opposite impression. It maintains all of the features of the partial equilibrium Marshallian S-D vision except the presumption that the unique globally attracting equilibrium is necessarily normatively appealing. Policy becomes simply a process of picking the right level of spending so that the economy naturally arrives at a good equilibrium, as opposed to a process of designing an institutional structure that would create an environment where a stable and non-pathological market outcome is possible in the first place.

The Solow growth model, also a staple of most intermediate macroeconomics courses, provides our third example of a pedagogical device exhibiting simple "stabilizing dynamics.” The Solow model aims to understand the long run evolution of output. It deliberately abstracts from business cycle fluctuations by positing that output at any moment of time depends only on the aggregate quantity of labor and capital in the economy via a simple production function. Capital (and hence output) evolves over time via two offsetting effects: investment and depreciation. Plausible assumptions are then made so as to ensure that depreciation dominates at high levels of capital, and capital accumulation dominates at low levels of capital. There is thus a unique intermediate "equilibrium” level of capital, which is a global attractor.

There is no question that this is a useful and informative model, so long as it is properly applied. Solow $(2008,244)$ gives some guidance on this:

\footnotetext{
${ }^{14}$ The view is discussed in more detail in the introductory chapter of Landreth and Colander (2002). There were many attempts to introduce this more dynamic interpretation of Keynesian work, but none of these were integrated into the textbooks. (Colander, 2006b)
} 
I restricted the applicability of the model to tranquil trajectories without stormy intervals... [and] I immediately warned the reader of the possibility of aggregative short to medium run imbalances that would not fit in to the model.

We would add that even the conception of a unique "long run" evolution of capital, while plausible, is hardly ensured in richer models.

For all their shortcomings as pedagogical tools, the equilibria in these examples are explicitly justified by an appeal to out-of-equilibrium dynamics (though the dynamics are only explicit in the Solow model). Except in the Solow model, where the dynamics are "interesting," appeals to out-of-equilibrium dynamics are made only to justify equilibrium; they are quickly suppressed thereafter and the model is used only for finding and studying the equilibrium itself.

\subsection{Examples where Stability Is Typically Suppressed}

We now turn to other parts of the undergraduate curriculum equilibrium concepts that are employed without any appeal to out-of-equilibrium dynamics to justify the attainment of equilibrium. As we discussed above, the use of the Keynesian Cross framework with its unique globally stable equilibrium to illustrate how the market can be persistently "stuck in a rut" is misguided. Nesting it within the IS-LM AS-AD framework eviscerates its rhetorical content yet further.

In the modern incarnation of the IS-LM ${ }^{15}$ model, short-run equilibrium is identified as the intersection of the IS and LM curves, when both goods and financial markets are in equilibrium. There is a plausible dynamic story for each curve: the Keynesian Cross for the former, and a simple S-D argument in money markets for the latter. But describing how the two markets simultaneously equilibrate is deliberately avoided, and students coming out of an intermediate course are unlikely to even be aware that two dimensional dynamical systems can have dynamics that are qualitatively different from onedimensional systems.

The AS-AD model adds a third market (labor markets) and a third equilibrium variable (the price level) to the IS-LM model. Again, the three-dimensional dynamics are intentionally suppressed. This is rather artfully accomplished: the AD curve is "derived" by varying the price level and tracing out how the IS-LM equilibrium level of output responds. Putting this curve together with the AS curve on a set of axes not only hides one of the equilibrium variables, it converts the whole system into one which misleadingly calls to mind the simple S-D dynamics again. ${ }^{16}$

\footnotetext{
${ }^{15}$ We focus here on the treatment in Blanchard (2008b), but similar (and in some cases more forceful) critiques could be leveled at every major intermediate macro text. There used to be more explicit discussion of the dynamics leading to equilibrium when the IS-LM framework was taught using the four-quadrant model. But even there, the dynamics were largely heuristic.

${ }^{16}$ See Colander (1995b) for a critique of the AS-AD pedagogical model.
} 
Finally, a "natural rate" of output or long-run aggregate supply curve is posited. It is “justified” by Marshallian S-D reasoning to argue for full employment in labor markets (perhaps with frictions to allow for some equilibrium unemployment). Once this natural rate of output has been introduced, there is a pedagogical pivot back to thinking about how dynamics "naturally" lead us back to the natural rate of output. A typical argument is that equilibria above the natural rate obtain because prices exceeded expectations. As expectations adjust and workers internalize the higher prices, the aggregate supply curve shifts up until the economy returns to the natural rate and adjustments cease. ${ }^{17}$

Introducing a temporal element to the AS-AD framework changes very little: it effectively amounts to replacing the AS curve with an expectations-augmented Phillips Curve, and the $\mathrm{AD}$ curve with a dynamic version of the equation of exchange. This yields a (discrete) dynamical system. The dynamics are interesting and pedagogically useful, but it is important to note that they capture only the dynamics of the movement from short-run AS-AD equilibrium back to the long-run natural rate. The assumption of period-by-period static equilibrium is maintained. Furthermore, the dynamics are again deliberately designed to yield global dynamic stability.

The artifice of assuming a "natural rate of output" is justified by an appeal to the full employment of resources, which is in turn justified by a Marshallian supply-and-demand argument-even though it is clear that aggregates like total output cannot be understood in partial equilibrium terms. But general equilibrium receives little attention in undergraduate curricula. ${ }^{18}$ And at the graduate level, general equilibrium is not justified with a compelling story about out-of-equilibrium dynamics at all. Indeed, by the time students learn about general equilibrium, equilibrium has become its own justification.

Undergraduate courses do frequently employ general equilibrium results. The Fundamental Welfare Theorems, for example, play a central role in public or health economics courses. Typically these theorems are justified using S-D reasoning about maximizing “total surplus” (or perhaps “proved” in an Edgeworth box economy). And even when the welfare theorems are not invoked explicitly, they are implicitly employed: For example, public finance texts differ dramatically from one another in their implicit view of the proper role of government, but they are unified in the view that without identifying a specific "market failure," there should be a presumption that the market outcome is efficient.

\footnotetext{
17 Alternative treatments of business cycles are becoming more popular. Treatments that replace the LM curve with a "Taylor Rule" are again built around a view of an economy fluctuating around the natural rate. The role for policy is to smooth those fluctuations by using an automatic monetary rule. (But notice that this eviscerates the main rationale for arguably the most important aspect of policymakers: avoiding major pathologies resulting from not being near the "natural” state.)

${ }^{18}$ If it is disussed, it is typically via an Edgeworth box, where the disequilibrium dynamics are entirely analogous to the simple supply-and-demand framework (except that uniqueness is no longer so obvious). It is only with three or more goods that the "dynamics" may no longer support the dynamic stability of equilibrium. At the graduate level, this is deftly illustrated for graduate students in the popular text MasColell, Whinston, and Green text (1995, 620-624), via a three-good Walrasian system with_tâtonnement dynamics.
} 
Nash equilibrium plays a unique role in economics. It is a rather distinct notion from classical equilibrium: it is frequently non-unique and inefficient. Unfortunately, courses in game theory are often heavy on techniques for solving for equilibrium and light on inquiries into why we should expect equilibrium to obtain. But there are good pedagogical presentations of game theory. These discuss alternative solution concepts such as rationalizability, and they discuss cooperative game solutions as well as noncooperative game solutions. In doing so they make it clear that game theory is just a framework for posing difficult questions, not a technique that provides definitive answers. Some game theory courses even explicitly consider disequilibrium dynamics with evolutionary games and laboratory experiments. These approaches can enrich the notions of equilibrium enormously by allowing interactions between biological, social, and economic variables (Bowles and Gintis 2005). Studying these leaves students with an amazement about the wealth of potential outcomes in our economy. We believe that this is precisely what we should be cultivating in the pedagogical core of economics.

\section{WHY IS ALL THIS A PROBLEM?}

The self-correcting "stability" vision cultivated by economic pedagogy is problematic in several respects. First and foremost, it is simply wrong: stability is not the norm in complex systems.

Second, it leads to false confidence that arguments in support of that vision, which have only been elaborated in simple partial equilibrium settings, are universally applicable. There are very good reasons to favor laissez faire policies. But the idea that market forces are "naturally" guiding the economy back to some unique and normatively appealing outcome is a fantasy, one which bright students can only sustain in the absence of competing visions of the behavior of dynamic systems.

Third, this vision maintains the growing rift between economics and the frontiers of science, particularly biology and applied physics. Given that policymakers are more likely to have studied economics than the other sciences, it is particularly important that they are at least exposed to alternative visions. Andrew Mellon provides the quintessential historical example of an important policymaker with an insufficiently broad vision of market dynamics, and any number of examples could be pulled from more recent times. Frankly, the thought that an official with no vision of dynamical systems other than a globally dynamically stable one being in charge of environmental policy or responding to financial crises is alarming.

For a concrete illustration of how good economists who lack the Marshallian vision go very wrong in their policy advice, consider a recent and well known article by Chari and Kehoe (2006). In it they argue for the direct policy relevance of the DSGE model. While we agree that it has some relevance, operating purely within the implied "global stability" vision of DSGE reasoning leads them seriously astray. Chari and Kehoe begin their article by lauding the extent to which recent theoretical advances in macroeconomic theory have found their way into policy. They write: 
Macroeconomics is now firmly grounded in the principles of economic theory. These advances have not been restricted to the ivory tower. Over the last several decades, the United States and other countries have undertaken a variety of policy changes that are precisely what macroeconomic theory of the last 30 years suggests. (p. 3)

and

[M]acroeconomic theory has had a profound and far reaching effect on the institutions and practices governing monetary policy and is beginning to have a similar effect on fiscal policy. The marginal social product of macroeconomic science is surely large and growing rapidly. (p. 26)

In a sharp response (2008), Solow, who maintains a Marshallian vision of the complexity of the aggregate economy, describes what they mean by a "firm" grounding:

They mean a macroeconomics that is deduced from a model in which a single immortal consumer-worker-owner maximizes a perfectly conventional time-additive utility function over an infinite horizon, under perfect foresight or rational expectations, and in an institutional and technological environment that favors universal price-taking behavior. (p. 243)

In other words, "firm foundations" refers precisely to the Sons-of-Samuelsonian vision of a model with a unique equilibrium that is always and instantaneously achieved. We have no problem with the DSGE model, but we do have a serious problem with researchers who take it seriously for policy. And Chari and Kehoe do take these models and the underlying vision quite seriously. They write:

The message of examples like these is that discretionary policy making has only costs and no benefits, so that if government policymakers can be made to commit to a policy rule, society should make them do so. (pp. 78)

Macroeconomists can now tell policymakers that to achieve optimal results, they should design institutions that minimize the time inconsistency problem by promoting a commitment to policy rules. However, to what particular policies should policymakers commit themselves? For many macroeconomists considering this question, quantitative general equilibrium models have become the workhorse model, and they turn out to offer surprisingly sharp answers. (p. 9)

Solow's critique of their article is aimed at the lack of sensibility it takes to view these models as universally good guides to policy. He clearly emphasizes that his seminal growth model was designed and articulated precisely to avoid applying it outside of the 
proper context. DSGE models (or at least some "small, transparent, tailored" version of them) can be instructive and useful, but they typically provide an inappropriate global vision.

Because they lack Solow's vision, Chari and Kehoe seem to miss the crux of Solow's objection entirely:

In this sense, we share Solow's preference for "small, transparent, tailored" models. However, answering the kinds of macroeconomic questions that we ask typically requires the use of general equilibrium models. (p. 247)

and

Yet that does not rectify what seems to be his [Solow's] principal complaint, which has to do with the order in which we do things. Modern macroeconomists generally start with a model with a single type of agent and then enrich it with the details necessary to answer the question at hand. Solow prefers to start with a model with eight types of agents and then trim away the unnecessary details, in order to end up with a small model. To answer any particular question, though, does it really matter that we start with a single type of agent and boost it to three types while he starts with eight types of agents and cuts back to three? (p. 248)

To interpret Solow's critique as being about "the order in which we do things" and to respond to Solow's preferences for partial equilibrium models by asserting that "answering the questions we typically ask requires the use of general equilibrium models" is to miss his point entirely: general equilibrium models may be entirely inappropriate for modeling the macro economy, for example because the dynamic foundations of equilibrium may make the achievement of equilibrium far less compelling. Partial equilibrium models may not be able to answer some questions easily, but at least we have good sense of when equilibrium is well founded. The general equilibrium models favored by Chari and Kehoe share the name "equilibrium" with simple partial equilibrium models, but they provide little in the way of justification that the dynamics are stabilizing and that the assumption is justified in any way.

As we discussed in the introduction, there have been attempts to provide dynamic foundations for DSGE models via models of out-of-equilibrium learning. We view the early lessons from these attempts as unsupportive of the DSGE approach. First, it has not been easy to find dynamics that guarantee any sort of convergence (Saari and Simon 1978). Second, learning dynamics that do converge in particular settings are not more (and probably are less) compelling than simpler ones for which convergence is not guaranteed: even if we can write down stabilizing learning dynamics, that does not mean market participants are actually learning that way. Third, even if market participants use a convergence-guaranteeing learning dynamic, the equilibrium may not coincide with the 
DSGE equilibrium: it will be a self-confirming equilibrium, but not necessarily a rational expectations equilibrium (Sargent 2008). ${ }^{19}$

In fact, the whole exercise of looking so hard for tractable learning dynamics that can "rationalize" equilibria by stabilizing them strikes us as a being a tell-tale of misguided vision (of the profession as a whole, if not of individual researchers): it stems from a view that equilibrium should be inherently stable separate from the institutional structure that endogenously develops to maintain stability. If we are correct that institutional structures develop endogenously to provide stability, then the hope of developing a simple model that abstracts from those institutional structures is ephemeral. This view lies firmly within a vision that borrows its intuition and justification from simple dynamics of S-D models, a vision within which many types of dynamics systems simply do not fit. It is a narrow, almost tunnel-like vision that would not arise naturally were it not actively cultivated.

We now turn to thinking about how to address the pedagogical shortcomings that cultivate this vision.

\section{WHERE DO WE GO FROM HERE?}

We see three potential (and closely related) solutions to the tendency of economics to impart to its students the vision of global dynamic stability. The first approach would be to radically overhaul the structure of the economics curriculum by making simulation, agent-based modeling, and pattern recognition the organizing themes. Joan Roughgarden's book in evolutionary ecology (Roughgarden 1998) is an example from another field. This could involve re-designing the introductory course to center on illustrative examples of complex systems such as the game of life, the Shelling model, and perhaps examples of chaotic models. We view this approach as promising, particularly as a way of unifying social sciences in general. But it seems unlikely to gain much purchase within economics in the short and intermediate run, in part because it does not feel like economics. Moreover, such a movement would shift focus away from opportunity costs and the implications of constrained optimization, both of which are useful and considered necessary by many professors. In the long run, we might hope that this is an approach that helps to unify social science, but it is not a plausible short or medium run goal.

A second approach would be to re-organize the economics curriculum around game theory instead of supply and demand. This has several advantages. First, game theory feels more like economics than does simulation. (Indeed, along with Walrasian equilibrium, it is arguably the organizing vision in modern economics research.) Second, game theory and S-D both revolve around a notion of "equilibrium.” The advantage of game theory is that equilibrium is generally not unique in game theory, and it is not always efficient, and, perhaps most importantly, it is not obvious that it is even globally stable. Even in the paradigmatic Prisoners' Dilemma game, where equilibrium is obvious,

\footnotetext{
${ }^{19}$ We additionally note that the "speed” of convergence is not well specified: so we don't know whether it is reasonable to operate "as if" the model has already converged.
} 
simple tournaments and experiments can show that it is not necessarily what emerges from actual play (Axelrod 1984). Game theory also ties economics more effectively to biology, and, indeed, simulations of simple evolutionary game-theoretic systems can yield surprisingly complex outcomes. Someone with a game-theoretic view of the world would be a much different person than someone with the view inculcated by the S-D paradigm. We view this as a potentially fruitful direction in the intermediate term; Samuel Bowles's intermediate micro book (Bowles, 2005) is a pioneering step in this direction.

In the short term, re-orienting economic pedagogy in the principles around game theory may be too ambitious - though as courses in game theory increasingly become required for degrees in economics, they can and should play an important role in softening the S-D frame. This leads us to suggest a third, more modest, approach: introduce skepticism about the robustness of "natural" stability of economic systems right from the get-go by adding a few more of the Marshallian zig-zags in the discussion of models. In particular, we envision telling a series of stories about disequilibrium dynamics and expectations using the cobweb model and a sequence of modifications. (A similar approach is advocated by Brock (2000).) The key is to move beyond the simple heuristic story "if prices are too high, the result will be a surplus, forcing prices back down" and to do this by being explicit about the adjustment process.

Let us briefly discuss what we mean. Consider a market where suppliers make simultaneous production decisions based on price expectations, and instantaneous prices are determined from the aggregate production via a fixed demand curve. We are interested in the dynamics of price and quantity over time-in particular, in when they converge to equilibrium. These dynamics are driven by the nature of expectations. The simple cobweb model obtains when price expectations are formed by naïvely extrapolating the previous period's price. These naïve expectations are sufficient to stabilize the equilibrium in some markets (those with shallow demand curves and steep supply curves), but in other markets they are destabilizing, leading to prices that move farther and farther from equilibrium.

While it is implausible that these destabilizing cycles will continue for long, discussing how they are remediated is a useful exercise: one can explore the possibility of a shrewd middleman entering the market, buying at high prices and selling at low prices, profiting while stabilizing the system.

A possibility more closely tied with modern methods is to allow suppliers to ditch their naïve expectation formation rules in favor of a rule with more "foresight." Brock and Hommes (1997) consider a simple and intuitive model of this: individuals in this model can "buy" rational expectations for a small cost, or else can rely "for free" on naïve expectations. Suppliers "switch" expectations quickly (but not infinitely quickly) when one of the strategies is more profitable. The suppliers here are smart, purposeful, and forward-looking. (Indeed, we would assert that this is arguably a much more realistic model than both perfect naïveté and perfect and costless foresight.) And the dynamics it produces are extremely rich. 
Figure 1 plots an illustrative example of the evolution of prices over time in such a model. Prices behave very oddly here. In the early periods, the dynamics seem to suggest quasi-stability: prices fluctuate, but within a few days they seem to settle down close to the new equilibrium. Stability of equilibrium looks pretty good. That is, it looks good until about day 40, when suddenly, and apparently without any external shock, prices begin to diverge, moving close to $10 \%$ lower and 5\% higher within just a few days. Then prices settle back down to about those of day 40 again for a few days, until, suddenly, they fluctuate wildly again. Then they settle down for a long time again, and so it goes. What we see, in short, are extended periods where equilibrium is an excellent approximation to the price that actually obtains in the market. But the system can hardly be said to be stable: it goes through cyclical—but aperiodic and unpredictable-periods of significant instability.

A particularly nice feature of Brock and Hommes' model is that there is a natural economic interpretation of this pattern. For prices close to the equilibrium price, it is not very costly to rely only on naïve expectations, so most suppliers choose to "free ride" rather than paying a cost to be able to make only marginally better predictions. But when most types are naïve, the equilibrium is unstable and prices tend to spiral away from it. When prices get sufficiently far from equilibrium, supplier's bad predictions lead them to suffer enough to make it worthwhile investing in the better prediction technology and becoming better informed. These better expectations re-stabilize the market. Importantly, note that these periods of instability occur at seemingly random times (and, in fact, the times are actually random in the formal sense). ${ }^{20}$

Beyond providing a pedagogically useful counterweight to the stability metaphor inculcated by the standard S-D model, we view the dynamics the Brock-Hommes model produces — and the intuition behind those dynamics - as a useful metaphor for real economic phenomena. For example, financial crises that occur after periods of stability lead individual and regulators to "forget" that they can happen. The wild swings induced by the crisis then lead to the re-imposition of regulatory and expectational controls that re-stabilize the system.

As a theoretical model, the Brock-Hommes model has problems-it is ad hoc, and its dynamics don't look anything like real market dynamics. Moreover, it suggests that if somehow agents were just "better" at pursuing their self-interest, the system would be able to achieve an equilibrium. We accept all those limitations. But as a pedagogical model that gives students a sense that there can be problems arriving at and maintaining equilibrium even in simple models, we find it a useful counterbalance to the current presentations. Indeed, the point is to argue that even if the system can ultimately be stabilized, that stability can be much harder to justify than standard presentations of the S-D model suggest.

\footnotetext{
${ }^{20}$ These issues are nicely discussed in Hommes et al., 2001.
} 
For example, it is pedagogically useful to note that imposing perfectly rational expectations would restore "globally stable dynamics" in the Brock-Hommes framework. The hope in employing "rational expectations" models is presumably that they are a useful approximation - they are obviously not literally correct. An advantage of the Brock-Hommes model, in our view, is that it invites a bit of skepticism about this hope: the model seems like an eminently reasonable approximation to "rational expectations" but nevertheless gives dynamics with a drastically different flavor. ${ }^{21}$ It is this diversity of flavors that we are suggesting needs to be actively cultivated in the texts.

\section{CONCLUSIONS}

Vision is important, and it is given too little emphasis in economic pedagogy. Marshallian economics worked because it provided multiple visions — a market supplyand-demand vision of a unique global attractor with simple dynamics relevant for small submarkets, supplemented by a broader Classical complexity vision of multi-market settings, settings with complex and potentially chaotic dynamics. Thus in the preface to his Principles Marshall wrote that "the Mecca of the economist is economic biology rather than economic dynamics" (1920, xiv), and that the mathematics of general equilibrium theory lies in thermodynamics. The problem for Marshall was that his readers did not have the mathematical expertise to explore that complexity vision technically, even if he did understand it. But he wanted to let the reading public know that these issues were important, and thus he chose to deal with them through the zig-zag windings of the flowery path of literature.

Keynes extended this Marshallian complexity vision to the aggregate economy, but the macroeconomic complexity vision was soon lost in pedagogical models that reduced “Keynesian” economics to equilibrium models with simple dynamics. Early macro economists such as Goodwin, Frisch, and Samuelson recognized the problem, and initially students were introduced to these problems through the multiplier accelerator model and Harrod's knife edge growth model, but these quickly faded from the texts, and were replaced by a simpler vision. Instead of moving to a reasonable pedagogical equilibrium immediately, the profession zigged when it should have zagged.

The reason for the zig is that it wanted to avoid the flowery path, and the mathematics necessary for the study of complex dynamics was both not sufficiently developed, and too complicated, to include it any other way than verbally. The initial economists, such as Samuelson and Solow, who led us down the mathematical path were trained in the Marshallian vision, and took it for granted that any reasonable person would share that complexity vision, and use models accordingly. They taught their students to become proficient in the supply-and-demand framework and to think about all economic problems in terms of small, transparent models that could be specified mathematically.

\footnotetext{
${ }^{21}$ Qualitatively similar dynamics can emerge in general equilibrium settings, too. In an innovative recent paper, Gintis (2007) has argued that similar adaptation rules in a multi-market context with private rather than public prices can provide something akin to stability. The dynamics Gintis describes are qualitatively similar to Brock and Hommes's (1997) single-market model dynamics: the market is typically stable most of the time, but occasionally and unpredictably moves decisively away.
} 
This led to the Sons-of-Samuelsonian vice of believing that that was the only way to think about the economy, and that all economists' models had to be small, transparent models, and not to recognize that these "small, transparent models" had to fit into a broader visions for them to be useful. Chari and Kehoe are the "Sons of Samuelson and Solow" and they are an example of what happens when the broader Marshallian vision is lost.

The problem is not only with DSGE modelers such as Chari and Kehoe. The problem goes deeper, and is responsible for economists failing to warn society that the macro economy may be unstable, thus leaving society totally unprepared for the recent financial crisis that almost led to a second great depression. This failure suggests that there is a systemic failure in the economics profession. (Colander et al., 2008).

When economists in the 1920s fell into such a vision, they were knocked out of it by the Great Depression, which made it clear that the complex dynamics within the system can affect the economy in highly undesirable ways. We suspect that if another Great Depression hits the world economy, economic pedagogy will change, just as it did in the 1930s. Unfortunately, the close call of the last two years does not seem to have been enough to bring about either a policy or a pedagogical change to reflect the fact that it is likely that the macro economy faces serious problems of systemic instability as is evidenced by the slow pace of major regulatory reform. Much of the policy discussion involves thinking of the recent episode as just a large and deep recession, rather than a serious warning that macro economies can exhibit enormous instability that needs to be planned for even when, and perhaps most actively when, times are seemingly good.

There seems to be an attractor in economic pedagogy that pulls it toward a model that explains the current state of the economy, whatever that state is. The lack of a depression, and the lack of any training of economics students in economic history, and the sole emphasis on models with stable dynamics have influenced the learning dynamics in the profession, leading the profession away from Marshall's complexity vision of the aggregate economy. It is our hope that it does not take another global depression to get economic pedagogy out of its current rut. 


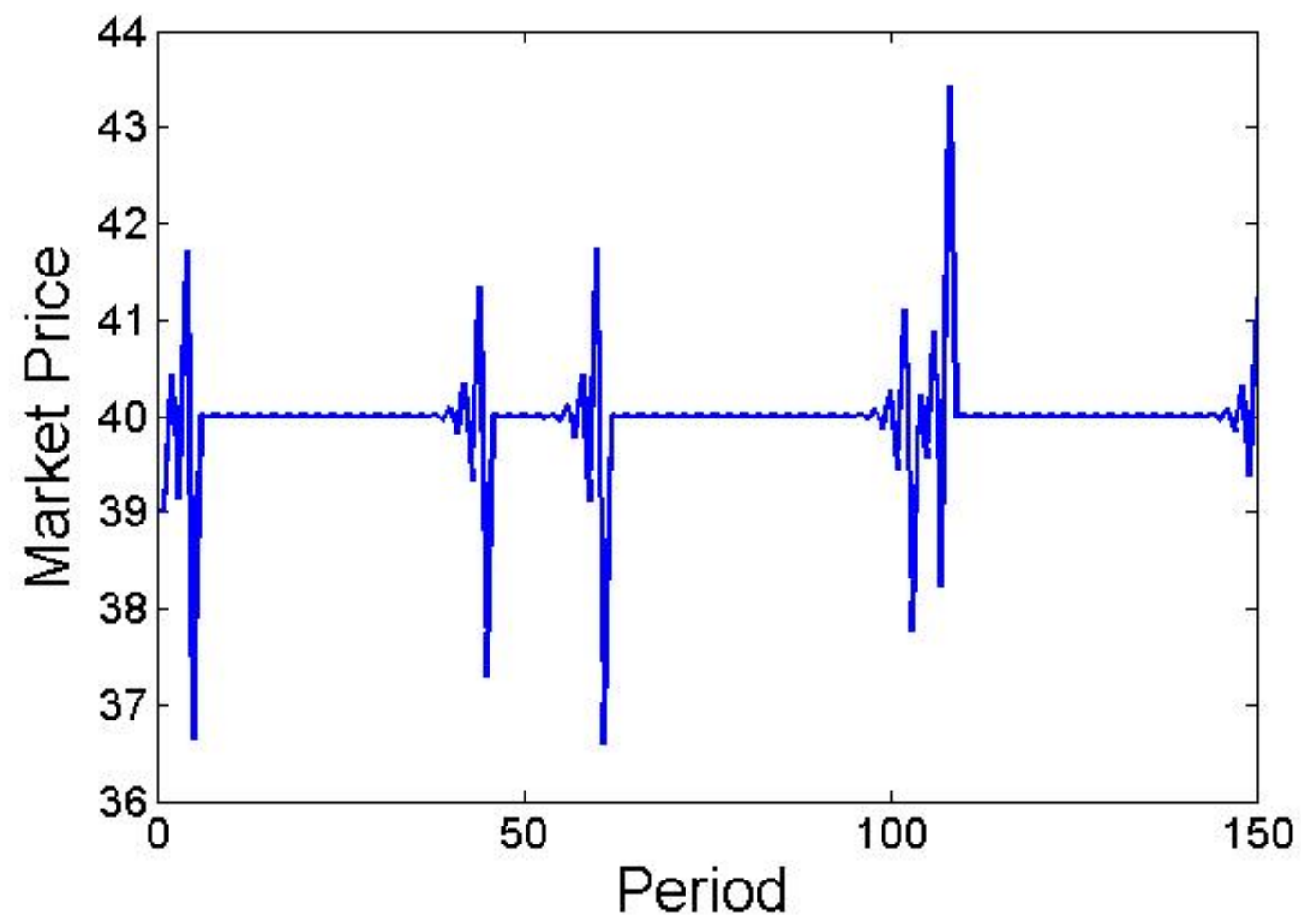

Figure 1: The evolution of price over time under the Brock and Hommes (1997) dynamics. The simulation uses a supply curve: $Q^{S}=P$, a demand curve $Q^{D}=60-\frac{1}{2} P$, a cost of 5 to be "perfectly rational," and a switching rate $\beta=3$ (which parameterizes the rate at which suppliers switch to adopt (away from using) perfectly rational expectations as opposed to naïve expectations when the former (the latter) is more profitable. In period 0 , prices are initialized to 39 , and we take $55 \%$ of individual firms to be employing rational expectation. 


\section{References}

Axelrod, R., 1984. The Evolution of Cooperation. New York: Basic Books. Blanchard, O., 2008a. The state of macro. NBER Working Paper 14259.

Blanchard, O., 2008b. Macroeconomics ( $5^{\text {th }}$ ed.). Upper Saddle River, NJ: Prentice Hall. Bonk, R., 2009. The Romantic Economist. Cambridge: Cambridge University Press.

Bowles, S., 2006. Microeconomics: Behavior, Institutions, and Evolution. Princeton: Princeton University Press.

Bowles, S., Gintis, H., 2005., Prosocial emotions. In: Blume L., Durlauf, S. (Eds.). The economy as an evolving complex system III: Essays in honor of Kenneth Arrow. Oxford, England: Oxford University Press, 337-67.

Brock, W., 2000. Some Santa Fe Scenery. In Colander, D. (Ed.). The Complexity Vision and the Teaching of Economics. Cheltenham, England: Edward Elgar, 29-49.

Brock, W., Hommes, C., 1997. A rational route to randomness. Econometrica, 65, 10581095.

Chari, V.V., Kehoe, P., 2006. Modern macroeconomics in practice: How theory is shaping policy. Journal of Economic Perspectives 20(4), 3-28.

Colander, D., 1995a. Marshallian general equilibrium. Eastern Economic Journal 21, 281-293.

Colander, D., 1995b. The stories we tell: A reconsideration of AS/AD analysis. Journal of Economic Perspectives 9(3), 169-188.

Colander, D. (Ed.), 1996. Beyond Micro foundations: Post Walrasian Macroeconomics. Cambridge, England: Cambridge University Press

Colander, D. (Ed), 2000. The Complexity Vision and the Teaching of Economics. Cheltenham, England: Edward Elgar.

Colander, D., 2006a. What we taught and what we did: The evolution of U.S. economic textbooks (1830-1930). Il Pensiero Economico Italiano XIV.

Colander, D. (Ed.), 2006b. Post Walrasian Macroeconomics: Beyond the DSGE model. Cambridge, England: Cambridge University Press.

Colander, D., 2007. The making of an economist redux. Princeton, NJ: Princeton University Press.

Colander, D., Rothschild, C., 2009. The complexity vision as a bridge between graduate and undergraduate macro. In Fofana, G., Setterfield, M. (Eds.). Macroeconomic Theory and Macroeconomic Pedagogy. New York and Basinstoke, England: Palgrave Macmillan.

Colander, D., Landreth, H., 1996. The Coming of Keynesianism to America. Cheltenham, England: Edward Elgar.

Colander, D., Kirman, A., Goldberg, M., Sloth, B., Juselius, K., Haas, A., Lux, T., 2008.The financial crisis and the systemic failure of the economics profession. Critical Review.

Debreu, G., 1974. Excess demand functions. Journal of Mathematical Economics 1, 1521.

Edgeworth, F., 1925. Papers Relating to Political Economy. (Originally, Presidential Address delivered to the British Association, 1889.) New York: Burt Franklin.

Foley, D., 2009. Complex systems “far from equilibrium” and economic causation. Unpublished paper. 
Gintis, H., 2007. The dynamics of general equilibrium. Economic Journal 117, 12801309.

Harden, B., 2007. Japan’s sacred bluefin, loved too much. Washington Post, A01, (September 11).

Harford, T., 2005. The Undercover Economist. Oxford, England: Oxford University Press.

Hart, S., Mas-Colell, A., 2003. Uncoupled dynamics do not lead to Nash equilibrium. American Economic Review, 93. 1830-1836.

Hazlitt, H., 1948. Economics in one lesson. New York: Pocket Books.

Holland, R., 1998. Bluefin tuna prices hit rock bottom. Boston Business Journal. (September 11). Retrieved September 19, 2008, from http://www.bizjournals.com/boston.

Hommes, C.H., Rosser, J.B., Jr., 2001. Consistent expectations equilibria and complex dynamics in renewable resource markets. Macroeconomic Dynamics 5, 180-203.

Landreth, H. Colander, D., 2002. History of Economic Thought. Boston: HoughtonMifflin.

Leijonhufvud, A., 1995. Hicks, Keynes and Marshall. In Hagemann, H., Hamouda, O. (Eds.). The Legacy of Hicks: His Contributions to Economic Analysis (pp. 147-162). New York and London: Routledge.

Johnson, K., 2008. Drop of oil: Be careful what you wish for. Environmental Capital, WSJ.com. (September 18) Retrieved September 19, 2008, from http://blogs.wsj.com/environmentalcapital.

King, N., 2008. Oil’s rapid rise stirs talk of \$200 a barrel this year. Wall Street Journal. (July 7.) Retrieved September 19, 2008, from http://online.wsj.com

Mantel, R., 1974. On the characterization of aggregate excess demand. Journal of Economic Theory 7, 348-353.

Marshall, A., 1890. Principles of Economics (1 ${ }^{\text {st }}$ edition). London: Macmillan and Co., Ltd.

Marshall, A., 1920. Principles of Economics ( $8^{\text {th }}$ edition). London: Macmillan and Co., Ltd.

Mas-Colell, A., Whinston, M., Green, J., 1995. Microeconomic Theory. Oxford, England: Oxford University Press.

McCloskey, D., 1996. The vices of economists, the virtues of the bourgeoisie. Amsterdam: Amsterdam University Press.

Meyer, G., 2008. Oil prices decline despite output cut. Wall Street Journal. (September 11.) Retrieved, September 19, 2008, from http://online.wsj.com.

Mill, J.S., 1838. Essay on Bentham. In Leavis , F. R. (Ed.), 1950. Mill on Bentham and Coleridge. London: Chatto and Windus.

Pantalioni, M., 1889. Pure Economics, translated by T. Boston. Bruce, New York: Kelly and Millman, 1898.

Pigou, A. C., 1925. (ed.), Memorials of Alfred Marshall (repr. 1966) London: Macmillan..

Rosser, B., 1991. From catastrophe to chaos: A general theory of economic discontinuities, mathematics, microeconomics, macroeconomics, and finance. New York and London: Kluwer Academic Publishers. 
Rosser, B., 1999. On the complexities of complex economic dynamics, Journal of Economic Perspectives 13 (4), 169-192.

Roughgarden, J., 1998. Theory of Population Genetics and Evolutionary Ecology: an Introduction. New Jersey: Prentice Hall.

Samuelson, P., 1947. Foundations of Economic Analysis. Cambridge, MA: Harvard University Press.

Samuelson, P., 1948. Principles of Economics. New York: McGraw Hill.

Samuelson, P., 1967. The monopolistic competition revolution. In E. Kuenne, (Ed.). Competition Theory. New York: John Wiley, 105-138.

Samuelson, P., 1996. Interview with Paul Samuelson. In Colander, D., Landreth, H. The coming of Keynesianism to America. Cheltenham, England: Edward Elgar, 145-178.

Samuelson, P., 1972. Maximum principles in analytical economics. American Economic Review 62(3), 249-62.

Samuelson, P., 1974. Remembrances of Frisch. European Economic Journal, 5(1) 7-23.

Sargent, T., 2008. Evolution and intelligent design. American Economic Review 98(1), 5-37.

Saari, D., Simon, C., 1978. Effective price mechanisms. Econometrica 46(5), 1097-1125.

Solow, R., 2008. The state of macroeconomics. Journal of Economic Perspectives 22(1), 243-249.

Sonnenschein, H., 1972. Market excess demand functions. Econometrica 40, 549-563.

Tabarrok, A., 2008. Response to my mother. Blog entry posted to www.marginalrevolution.com. Retrieved September 14, 2008.

Velupillai, K. V., 2008. Taming the incomputable, reconstructing the nonconstructive and deciding the undecidable in mathematical economics. Mimeo. 